\title{
Investigating pellet charring and temperature in ultrasonic vibration-assisted pelleting of wheat straw for cellulosic biofuel manufacturing
}

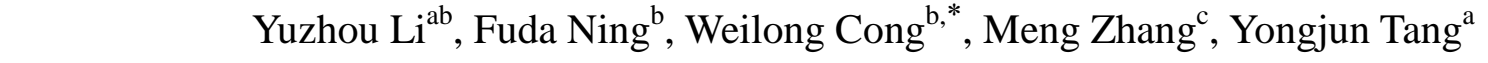

a School of Electromechanical Engineering, Guangdong University of Technology,

6 Guangzhou, Guangdong 510006, China.

b Department of Industrial Engineering, Texas Tech University, Lubbock, TX 79409, USA.

c Department of Industrial and Manufacturing Systems Engineering, Kansas State University, Manhattan, KS 66502, USA.

Abstract

Biofuels are only alternative solution for liquid transportation fuels among different kind of renewable energy. To avoid the competition with the food, cellulosic biomass has been proposed as feedstock for manufacturing of cellulosic biofuels. Costs associated with collection, transportation, and storage of cellulosic biomass account for more than $80 \%$ cost of the feedstock.

By processing cellulosic biomass into high density pellets, handling efficiency of cellulosic

7 feedstocks can be improved, leading to costs reduction in transportation and storage. Ultrasonic vibration-assisted (UV-A) pelleting is a recently developed pelleting method, which can not only

\footnotetext{
* Corresponding author. Tel: +1 806834 6178; fax: +1 8067423411.

E-mail address: weilong.cong@ttu.edu(W.L. Cong).
} 
19 produce higher density but also break the lignin shell, to some extent, to increase cellulose

20 accessibility and then increase sugar and biofuel yield. The reported investigations on UV-A

21 pelleting provided little information about the relationship between charring and pelleting

22 temperature under different input variables of pelleting. In this paper, effects of different input

23 variables of pelleting on both charring ratio and pelleting temperature were studied. This paper,

24 for the first time, reported the relationship between charring ratio and pelleting temperature. The

25 obtained results will be helpful in understanding the mechanism of UV-A pelleting and providing

26 guide to control pellet charring for a higher biofuel yield.

27

28 Keywords

29 Charring, temperature, ultrasonic vibration-assisted pelleting, biofuel, cellulosic biomass

$31 \quad 1$ Introduction

32 The most commonly used transportation fuels are petroleum-based fuels, whose supplies are

33 expected to decline in the future $[1,2]$. Biofuels including bioethanol and biodiesel alternatives

34 to petroleum-based transportation fuels can potentially dampen price volatility in transportation

35 fuels, reduce economic and security concerns related to importing oil from other countries, and

36 reduce the greenhouse gas (GHG) emissions along with associated risks of global climate change

37 [1-3]. Currently, primary feed materials for biofuels manufacturing are sugarcane (in Brazil),

38 corn (in U.S.), and rapeseed (in Europe). The use of edible crops for biofuels manufacturing may

39 result in increasing of food price. Therefore, it is crucial to utilize no-food crops for biofuels 
40 manufacturing, and cellulose biomass feedstock. Cellulosic biomass includes agricultural

41 residues, forestry and wood pulp wastes, and energy crops [5, 6]. The U.S. government expects

42 that annual production of cellulosic biofuels will reach to 16 billion gallons by 2022 , and

43 cellulosic biomass can be available in the U.S. for biofuels manufacturing to meet $30 \%$ of the

44 current transportation fuel consumptions $[4,7]$.

45

$46 \quad$ Figure 1 shows major steps for cellulosic biofuels manufacturing [8,9]. The low density of

47 cellulosic feedstocks is a main barrier hindering large-scale and cost-effective manufacturing of

48 cellulosic biofuels [10-13]. Under certain conditions, costs of biomass collection, transportation,

49 and storage account for more than $80 \%$ of feedstock cost [14]. Cellulosic biomass densification

50 will increase density, improve handling efficiency $[15,16]$, and reduce transportation and storage

51 costs [17-19]. Pelleting is a popular process to process cellulosic biofuels into pellets.

53 Traditional pelleting methods (for example, using a screw extruder, a briquetting press, or a

54 rolling machine $[18,20-23])$ generally require high-temperature steam, high pressure, and/or

55 binder materials, making it difficult to realize cost-effective pelleting on or near the field where

56 cellulosic biomass is available. Ultrasonic vibration-assisted (UV-A) pelleting, without using

57 high-temperature steam and binder materials, can produce pellets whose density is comparable to

58 that processed by traditional pelleting methods [24-26]. Moreover, biomass (switchgrass)

59 processed by UV-A pelleting has approximately $20 \%$ higher sugar yield (approximately

60 proportional to biofuel yield) than biomass pelleted without ultrasonic vibration [24]. 
62 The reported experimental investigations in UV-A pelleting include effects of pelleting 63 parameters on pellet quality, pelleting temperature, charring, and sugar yield [24, 27-38]. Under

64 certain UV-A pelleting conditions, charring occurs inside pellets produced. As shown in Figure 2,

65 charring occurred inside the pellet, and outside of the pellet might look was normal before pellet

66 being separated into halves. An experimental study on charring of cellulosic biomass in UV-A

67 pelleting has been carried out by Feng et al. [27], however, it is still unclear about the reasons of

68 pellets charring generating. The pellets charring may be resulted from high pelleting temperature

69 generated by ultrasonic vibration in UV-A pelleting. Currently, there are no reported studies on

70 the relationship between charring ratio and pelleting temperature. Therefore, it is necessary to

71 explore the optimal pelleting temperature for a low charring ratio with further obtaining a high

72 biofuel conversion yield.

73

74 In this paper, effects of various input parameters (pelleting duration, ultrasonic power, pelleting

75 pressure, pellet weight, and moisture content) on charring ratio and temperatures at three

76 different locations (at the center, on the top and bottom of a pellet) were studied. In addition, the

77 relationship between charring ratio and pelleting temperature in UV-A pelleting was explored.

78 The obtained results will contribute to the understanding of the influences of pelleting

79 parameters on both charring ratio and temperature for obtaining decreased charring with high 80 yield of biofuel. 


\section{$82 \quad 2$ Experimental conditions and procedures} 2.1 Biomass material and feedstock preparation}

The cellulosic biomass used in this study was wheat straw collected from a farm in western

Kansas. The wheat straw was run through a combine (9600, John Deere, Moline, IL, USA). The wheat straw and chaff exited through the back of the combine. The straw chopper on the combine was disconnected to allow the straw to be baled. The longest pieces of wheat straw coming out from the combine were $28 \mathrm{~cm}$ long.

Before pelleting, wheat straw was milled into powder by a knife mill (SM 2000, Retsch,

Germany). The particle size of wheat straw powder was controlled by a sieve with $2 \mathrm{~mm}$ in size in the knife mill. The mill used a three-phase, 240 volt, and 3 horsepower electric motor with fixed rotation speed of $1720 \mathrm{rpm}$.

Moisture content of cellulosic biomass was determined according to ASABE standard S358.2 DEC1988 [28] and National Renewable Energy Laboratory (NREL) technical report [29]. After measuring the initial moisture content of wheat straw powder, a certain amount of distilled water was sprayed on the wheat straw powder to adjust the moisture content to a desired level.

\subsection{Experimental setup}

Figure 3 illustrates the experimental setup. A modified ultrasonic machine (Model AP-1000,

102 Sonic-Mill, Albuquerque, NM, USA) was used to conduct pelleting. The experimented setup 
included an ultrasonic system, a pneumatic loading system, and a data-acquisition system. The ultrasonic system consisted of a power supply (which converted $60 \mathrm{~Hz}$ line electricity to $20 \mathrm{kHz}$ high-frequency electrical energy) and an ultrasonic transducer (which converted high frequency electrical energy into ultrasonic vibration). An aluminum mold with a cylindrical cavity at its center was used to hold wheat straw powder and shape the pellets. A pellet was compressed by solid cylindrical tool. Diameter of the tool $(17.4 \mathrm{~mm})$ was slightly smaller than that of the mold cavity $(18.6 \mathrm{~mm})$. In addition, the pneumatic loading system provided the pelleting force. A double acting pneumatic cylinder was mounted on the top of the aluminum protecting tube which was in conjunction with the ultrasonic transducer and protect the spindle. The pneumatic cylinder was driven by compressed air provided by a 1.6 horsepower air compressor (Sears, Roebuck and Co., Hoffman Estates, IL, USA), and its movement was controlled by a two-position and five-way manual valve. The air pressure in the cylinder was controlled by a pressure regulator.

\subsection{Experimental conditions}

Experimental conditions were shown in Table 1. One combination of pelleting input variables was used at a time. Pelleting duration was the period of time from the beginning to the end of a pelleting test, during which the tool was in contact with the wheat straw powder inside the mold. Pelleting time referred to the time between the beginning of a pelleting test till a point of interested time. Pelleting time could be any value between starting point and pelleting duration in this paper. The frequency of ultrasonic vibration was set at $20 \mathrm{kHz}$. Vibration amplitude was 
ultrasonic vibration. A higher pelleting pressure meant a higher pressure applied through the tool on wheat straw powder in the mold. Pellet weight was the weight of wheat straw powder in the mold cavity for each pellet.

\subsection{Measurement procedure for charring ratio}

Charring severity of pellets was evaluated by charring ratio (the ratio of the weight of charred biomass to the initial weight of the biomass). It could be calculated by the following equation:

$$
\text { Charring ratio }=\frac{\text { Initial biomass weight }- \text { Uncharred biomass weight }}{\text { Initial total biomass weight }}
$$

Charred biomass could be easily distinguished from the uncharred biomass, because the color of the charred biomass turned to dark. The pellet was broken into halves (as shown in Figure 2) across the diameter to remove charred biomass from the pellet. The separation of charred biomass and uncharred biomass was conducted manually since charring gave biomass a darker color. The weight of the biomass was measured by an electronic scale (TAJ 602, Ohaus, Pine Brook, NJ, USA).

\subsection{Measurement procedure for pelleting temperature}

The metal wire-type thermocouple (Type K) method was used for temperature measurement.

During the pelleting process, the thermocouples were pre-inserted inside biomass powder in the mold cavity through the slot at three locations (top, center, and bottom), as shown in Figure 4, to measure the temperatures at the top, center, and bottom of the pellet, respectively. The mold was specially designed with a through-slot where the thermocouples could freely move up and down 
145 to avoid being sheared. The thermocouples were connected to a thermometer (HH147U, 146 OMEGA Engineering, Inc., Stamford, CT, USA) and the measured data (temperature vs. time) 147 was recorded by a computer. Figure 5 shows typical temperature curves with $40 \%$ ultrasonic 148 power. Temperatures at all three locations (T1, T2, and T3) gradually increased over time. The 149 temperature at pellet center (T2) was always the highest among the three temperatures. 150 Maximum value of T2 curve was used to represent temperature in experimental results on effects 151 of input variables.

\section{Experimental results and discussion}

\section{$154 \quad 3.1$ Effects of ultrasonic power}

Figure 6 shows the temperature comparisons at different locations under various ultrasonic

powers from $40 \%$ to $70 \%$. Data points represent the average value and the error bars in Figure 6 , as well as in Figures 7 to 12, represent the maximum and the minimum values of temperature, respectively. It can be seen that at different levels of ultrasonic power, the temperature (T2) at center of pellet was always higher than the temperature (T1) at the top of pellet that was slightly higher than temperature (T3) at the bottom of pellet. In addition, with the increase of ultrasonic power, all the temperatures at all three locations increased accordingly. 
both variables could be found when ultrasonic power increased from $40 \%$ to $50 \%$ and from $60 \%$ to $70 \%$, while the increase was slight with the increase of ultrasonic power from $50 \%$ to $60 \%$. The increases of charring ratio and temperature for different levels of ultrasonic power were $70 \%$ and $170{ }^{\circ} \mathrm{C}$, respectively. The charring phenomenon in UV-A pelleting of cellulosic biomass was first reported in the experimental investigation by Feng et al [27]. Two types of cellulosic biomass, wheat straw and switchgrass, were employed. Similar observation was also reported that as the ultrasonic power increased the charring ratio increased. This trend was noticed for both biomass types. Charring only happened within a certain range of ultrasonic power (30-60\% for wheat straw and 50-60\% for switchgrass). Charring ratio was the highest for switchgrass when ultrasonic power was $60 \%$. Compared with wheat straw, switchgrass is less likely to char under same conditions. The possible reason of such phenomenon might be that with the increase of ultrasonic power, more vibration energy would be transferred to the pellets, leading to violent frictions among particles and particles vibrating inside the pellets. Therefore, more heat during UV-A pelleting would be generated and subsequently cause an increase of both temperature and charring ratio.

The relationship between the temperature and charring ratio at different levels of ultrasonic power can be seen in Figure 7c. It shows that there was no charring when the temperature was $180{ }^{\circ} \mathrm{C}$. When temperature increased from $180{ }^{\circ} \mathrm{C}$ to $350{ }^{\circ} \mathrm{C}$, charring ratio increased from $0 \%$ to $70 \%$. Especially, with the increase of temperature from $300{ }^{\circ} \mathrm{C}$, the charring ratio rapidly increased to $70 \%$. In addition, although both temperature and charring ratio increased as the 
ultrasonic power increased, the increasing rate of charring ratio versus ultrasonic power was

different from that of charring ratio versus temperature. There was an exponential relationship

between charring ratio and temperature under different levels of ultrasonic power. With the

increase of ultrasonic power, more violent frictions would be induced, leading to the increase of

temperature. At higher level of temperature, the same increase of temperature would result in a

larger charring ratio increase due to the inconsistent response of charring ratio to the temperature.

With this possible reason, the changing rate of charring ratio versus temperature would gradually increase, which contributed to an exponential relationship between charring ratio and temperature.

\subsection{Effects of pelleting pressure}

Figures $8 \mathrm{a}$ and $8 \mathrm{~b}$ show the effects of pelleting pressure on charring ratio and pelleting 
208 pellets and the particles inside the pellets would vibrate in high frequency. Particle violent 209 friction and vibration kinetic energy would generate more heat, leading to an increased pelleting 210 temperature and charring ratio thereafter. However, continuously increasing the pelleting 211 pressure to 50 psi would make the pellets much denser so that lots of ultrasonic vibration might 212 be directly transmitted through the pellet. Hence, the charring ratio and temperature would 213 decrease as the result of decreasing kinetic energy inside the pellets.

215 Figure 8c shows the relationship between the temperature and charring ratio under different 216 levels of pelleting pressure. The charring ratio remained at $0 \%$ before the temperature was above $217250{ }^{\circ} \mathrm{C}$. After that, at early stage, the increasing rate of charring ratio was remarkable, which 218 would be getting less with the further increase of temperature. The maximum value of charring 219 ratio $(35 \%)$ was obtained when the temperature increased to $320{ }^{\circ} \mathrm{C}$. It could be observed that 220 there was a logarithmic relationship between charring ratio and temperature with different 221 pelleting pressures.

\subsection{Effects of pelleting duration}

Effects of pelleting duration on charring ratio and temperature are shown in Figures 9a and 9b. It can be seen that there was no charring when the pelleting duration was $30 \mathrm{~s}$. Charring ratio and temperature had a similar trend with pellet duration and increased gradually as the pelleting duration increased from $30 \mathrm{~s}$ to $120 \mathrm{~s}$. Longer pelleting duration induced larger variances of charring ratio and temperature. Under a longer pelleting duration (120 s), more ultrasonic 
229 vibration energy was injected and more heat was accumulated in the pellet so that the 230 temperature and charring ratio would increase. Feng et al [27] also reported that the charring 231 ratio of UV-A pelleting of wheat straw $(\mathrm{MC}=20 \%$ and ultrasonic power $=50 \%)$ increased from 232 approximately $8 \%$ to $20 \%$ as pelleting duration increased from $60 \mathrm{~s}$ to $120 \mathrm{~s}$.

Figure 9c shows the relationship between the temperature and charring ratio at different levels of pelleting duration. The charring would not occur until the temperature increased to $150{ }^{\circ} \mathrm{C}$ and the charring ratio gradually increased as the pelleting temperature increased. The maximum average charring ratio was $32 \%$ with corresponding temperature of $275{ }^{\circ} \mathrm{C}$. There was a linear relationship between charring ratio and temperature with different pelleting durations. According to Figures 9a and 9c, the possible reason could be that the relationship between charring ratio and pelleting duration is similar to that between charring ratio and temperature.

\subsection{Effects of pellet weight}

Figures 10a and 10b show effects of pellet weight on charring ratio and temperature, respectively. It can be seen that there was a remarkable increase rate of charring ratio when pellet weight increased from $1.5 \mathrm{~g}$ to $2 \mathrm{~g}$ and a slow increase rate of temperature when pellet weight increased from $1.5 \mathrm{~g}$ to $2.5 \mathrm{~g}$. The temperature increased linearly with the increase of pellet weight. The

247 possible reason might be that pellet density was decreased with the increase of pellet weight under the constant pelleting pressure, leading to less ultrasonic vibration energy being 
the pellet.

252 From Figure 10c, it can be seen that when the temperature increased, the charring ratio increased

253 correspondingly. There was no charring occurring until the temperature was higher than $250{ }^{\circ} \mathrm{C}$.

254 After that, increasing rate of charring ratio was large at the beginning and gradually became

255 smaller. The charring ratio reached to maximum average value (38\%) when the temperature

256 increased to $310{ }^{\circ} \mathrm{C}$. It can be seen that charring ratio and temperature had a logarithmic 257 relationship at different levels of pellet weight.

\subsection{Effects of moisture content}

Effects of moisture content on charring ratio and temperature are illustrated in Figures 11a and

$11 \mathrm{~b}$, respectively. Both charring ratio and temperature remarkably increased with the increase of moisture content from $5 \%$ to $10 \%$ and from $15 \%$ to $20 \%$. When moisture content increased from $10 \%$ to $15 \%$, two variables had a slight increase. Feng et al [27] reported that the charring ratio of UV-A pelleting of wheat straw (ultrasonic power $=50 \%$ ) increased as the moisture content increased from $5 \%$ to $20 \%$. However, the biomass pellets did not have any charring when moisture content was $25 \%$ or higher. The possible reason could be that with the increase of moisture content, more water would be generated inside the pellets. Importing ultrasonic vibration to water might generate acoustic streaming and cavitation with output of more heat. Therefore, the temperature could be increased with more charring occurring thereafter. 
271 Figure 11c shows the relationship between the temperature and charring ratio. It can be found

272 that the relationship of charring ratio to moisture content was similar to that of charring ratio to

273 temperature. It can be found that with the increase of the temperature from $210{ }^{\circ} \mathrm{C}$ to $347{ }^{\circ} \mathrm{C}$, the

274 charring ratio increased almost linearly from $11 \%$ to $42 \%$.

275

276

3.6 Global overviews on relationship between charring ratio and pelleting

277 temperature

Figure 12 shows the global overviews on relationship between charring ratio and pelleting temperature under all different combinations of input variables. In general, there was a polynomial relationship between charring ratios and temperatures, and the charring ratio increased with the increase of the temperature. It can be seen that when temperature increased occurrence were different when different types of input variables increased. In addition, the maximum average value of charring ratio $(70 \%)$ would be obtained when temperature was about $350{ }^{\circ} \mathrm{C}$ at $70 \%$ of ultrasonic power.

\section{Conclusions}

291 In this paper, effects of different input variables including ultrasonic power, pelleting pressure, 
292 pellet duration, pellet weight, and moisture content on both charring ratio and pelleting 293 temperature were studied. This paper, for the first time, reported the relationship between 294 charring ratio and pelleting temperature. Major conclusions are:

295 (1) Charring always initially occurred at the center of a pellet. Also, the temperature at pellet center was always the highest among the temperatures at three locations in the pellet.

297 (2) Both charring ratio and temperature increased when ultrasonic power, pelleting duration, 298 pellet weight, and moisture content increased, and they first increased and then decreased when pelleting pressure increased.

300

(3) There was a correlation between charring ratio and temperature at pellet center. Charring ratio increased with the increase of temperature. The types of relationship between charring ratio and temperature and the critical temperatures for biomass charring happening were different with the increase of input variables.

304 The obtained results will be helpful in understanding the mechanism of UV-A pelleting and how 305 pelleting parameters affect charring ratio. The investigation of effects of input variables on 306 charring and relationship between charring ratio and temperature in UV-A pelleting is important to control pellet charring for a higher biofuel yield.

\section{Acknowledgements}

310 This study is supported by the Foundation of the Whitacre College of Engineering and the Office 311 of Vice President for Research at Texas Tech University and National Natural Science 312 Foundation of China (NSFC) through Grant 51275097. 
314

315

\section{References}

[1] Larsson, S.H., Rudolfsson, M., Thyrel, M, Örberg, H., Kalén, G., and Lestander, T.A., 2012, "Temperature controlled feed layer formation in biofuel pellet production," Fuel, 94(1), pp. 81-85.

[2] U.S. Energy Information Administration, 2011, “Annual energy review 2010," No. DOE/EIA-0384(2010), http://www.eia.gov/totalenergy/data/annual/pdf/aer.pdf.

[3] Stelte, W., Holm, J.K., and Sanadi, A.R., 2011, "Fuel pellets from biomass: The importance of the pelletizing pressure and its dependency on the processing conditions," Fuel, 90(11), pp. 3285-3290.

[4] 110th Congress, 2007, "Public Law 110-140," Energy Independence and Security Act of 2007, http://www.gpo.gov/fdsys/pkg/PLAW-110publ140/content-detail.html.

[5] Öhman, M., Boström, D., and Nordin, A., 2004, "Effect of kaolin and limestone addition on slag formation during combustion of wood fuels," Energy \& Fuels, 18(5), pp. $1370-1376$.

[6] U.S. Energy Information Administration, 2012, "Short-term energy outlook," http://www.eia.doe.gov/emeu/steo/pub/steo_full.pdf.

[7] Perlack, R., Wright, L., Turhollow, A., Graham, R., Stokes, B., and Erbach, D., 2005, "Biomass as feedstock for a bioenergy and bioproducts industry: the technical feasibility of a billion-ton annual supply," Oak Ridge National Laboratory, Oak Ridge, TN, USA.

[8] Gomez, L.D., Steele-King, C.G., and McQueen-Mason, S.J., 2008, "Sustainable liquid 
biofuels from biomass: the writing's on the walls," New Phytologist, 178(3), pp. 473-485.

335

336

337

338

339

340

341

342

343

344

345

346

347

348

349

350

351

352

353

354

[9] Rubin, E.M., 2008, “Genomics of cellulosic biofuels,” Nature, 454(14), pp. 841-845.

[10] Aden, A., Ruth, M., Ibsen, K., Jechura, J., Neeves, K., Sheehan, J., Wallace, B., Montague, L., Slayton, A., and Lukas, J., 2002, "Lignocellulosic biomass to ethanol process design and economics utilizing co-current dilute acid prehydrolysis and enzymatic hydrolysis for corn stover,” NREL/TP-510-32438. National Renewable Energy Laboratory, Golden, CO, USA.

[11] Phillips, S., Aden, A., Jechura, J., Dayton, D., and Eggeman, T., 2007, “Thermochemical ethanol via indirect gasification and mixed alcohol synthesis of lignocellulosic biomass," NREL Technical Report, TP-510-41168, National Renewable Energy Laboratory, Golden, CO, USA.

[12] Huber, G.W., 2008, "Breaking the chemical and engineering barriers to lignocellulosic biofuels: next generation hydrocarbon biorefineries," http://www.ecs.umass.edu/biofuels/Images/ Roadmap2008.pdf

[13] Waves, A., 2009, "Ethanol faces challenges ahead," http://naturalresourcereport.com/2009/08/ethanol-faces-challenges-ahead

[14] Accenture, 2011, "The United States and China: the race to disruptive transport technologies, implication of a changing fuel mix on country competiveness," http://nstore.accenture.com/acn_com/resources/Accenture_Energy_US_China_Report.pdf.

[15] Leaver, R.H., 1984, “The pelleting process,” Sprout-Waldron, Muncy, PA.

[16] Robinson, R.A., 1975, “The pelleting of millfeed," Bulletin Association of Operative 
Millers, July, pp. 3545-3549.

[17] Jensen, P.D., Temmerman, M., Westborg, S., 2011, "Internal particle size distribution of biofuel pellets," Fuel, 90(3), pp. 980-986.

[18] Sokhansanj, S., and Turhollow, A., 2004, "Biomass densification-cubing operations and costs for cornstover,” Applied Engineering in Agriculture, 20(4), pp. 495-499.

[19] Chin, O.C., and Siddiqui, K.M., 2000, "Characteristics of some biomass briquettes prepared under modest die pressures," Biomass and Bioenergy, 18(3), pp. 223-228.

[20] Mani, S., Tabil, L.G., and Sokhansanj, S., 2003, “An overview of compaction of biomass grinds," Powder Handling and Processing, 15(3), pp. 160-168.

[21] Faborode, M.O., 1990, "Analysis of extrusion compaction of fibrous agricultural residues for fuel applications," Biomass, 21(2), pp. 115-128.

[22] Mani, S., Tabil, L.G., and Sokhansanj, S., 2006, "Effects of compressive force, particle size and moisture content on mechanical properties of biomass pellets from grasses," Biomass and Bioenergy, 30 (7), pp. 648-654.

[23] Mani, S., Sokhansanj, S., Bi, X.T., and Tabil, L.G., 2004, "Compaction of corn stover," Proceedings of American Society of Agricultural and Biological Engineers (ASABE), St. Joseph, MI, pp. 1239-1249.

[24] Zhang, P.F., Pei, Z.J., Wang, D.H., Wu, X.R., Cong, W.L., Zhang, M., and Deines, T., 2011, "Ultrasonic vibration-assisted pelleting of cellulosic biomass for biofuel manufacturing," Journal of Manufacturing Science and Engineering, 133(1), pp. 011012-1-011012-7.

[25] Cong, W.L., Pei, Z.J., Zhang, P.F., Qin, N., Deines, T.W., and Lin, B., 2011, 
"Ultrasonic-vibration-assisted pelleting of switchgrass: effects of ultrasonic vibration," Transactions of Tianjin University, 17(5), pp. 313-319.

[26] Zhang, M., Song, X.X., Pei, Z.J., Deines, T.W., and Treadwell, C., 2012, "Ultrasonic-vibration-assisted pelleting of wheat straw: an experimental investigation," International Journal of Manufacturing Research, 7(1), pp. 59-71.

[27] Feng, Q., Cong, W.L., Zhang, M., Pei Z.J., and Ren, C.Z., 2011, “An experimental study on charring of cellulosic biomass in ultrasonic vibration-assisted pelleting," International Journal of Manufacturing Research, 6(1), pp. 77-86.

[28] ASABE Standard S358. 2 DEC1988, 2008, "Moisture measurement - forages," American Society of Agricultural and Biological Engineers, St. Joseph, MI, USA.

[29] Sluiter, A., Hames, B., Hyman, D., Payne, C., Ruiz, R., Scarlata, C., Sluiter, J., Templeton, D., and Wolfe, J., 2008, "Determination of total solids in biomass and total dissolved solids in liquid process samples," NREL Technical Report (NREL/TP-510-42621), National Renewable Energy Laboratory, Golden, CO, USA.

[30] Song, X.X., Zhang, M., Deines, T.W., Zhang, P.F., and Pei, Z.J., 2013, "Energy consumption study in ultrasonic vibration-assisted pelleting of wheat straw for cellulosic biofuel manufacturing," International Journal of Manufacturing Research, 8(2), pp. $135-149$.

[31] Feng, Q., Cong, W.L., Zhang, M., Pei, Z.J., Ren, C.Z., 2010, “An experimental study on temperature in ultrasonic vibration-assisted pelleting of cellulosic biomass," Proceedings of the ASME 2010 International Manufacturing Science and Engineering Conference 
[32] Zhang, P.F., Deines, T., Nottingham, D., Pei, Z.J., Wang, D.H., and Wu, X.R., 2010, "Ultrasonic vibration-assisted pelleting of biomass: a designed experimental investigation on pellet quality and sugar yield," Proceedings of the ASME 2010 International Manufacturing Science and Engineering Conference (MSEC), Erie, PA, October 12-15.

[33] Zhang, Q., Zhang, P.F., Deines, T., and Pei, Z.J., "Ultrasonic vibration-assisted pelleting of sorghum stalks: effects of pressure and ultrasonic power," Proceedings of the ASME 2010 International Manufacturing Science and Engineering Conference (MSEC), Erie, PA, October 12-15.

[34] Song, X.X., Zhang, M., Pei, Z.J., and Deines, T., 2010, "Ultrasonic vibration-assisted pelleting of cellulosic biomass: effects of moisture content," Proceedings of the ASME 2010 International Manufacturing Science and Engineering Conference (MSEC), Erie, PA, October 12-15.

[35] Zhang, P.F., Deines, T.W., Cong, W.L., Qin, N., Pei, Z.J., and Nottingham, D., 2010, "Ultrasonic vibration-assisted pelleting of switchgrass: effects of moisture content on pellet density, spring-Back, and durability," Proceedings of the 20th International Conference on Flexible Automation and Intelligent Manufacturing (FAIM 2010), California State University, CA, July 12-14.

[36] Zhang, Q., Zhang, P.F., Song, X.X., Zhang, M., Pei, Z.J., and Deines, T., 2011, “A study on amount of biomass pellets used in durability testing," Proceedings of the ASME 2011 International Manufacturing Science and Engineering Conference (MSEC), Corvallis, OR, 
June 13-17.

419

420

421

422

423

424

425

426

[37] Zhang, Q., Zhang, P.F., Deines, T.W., Zhang, M., Song, X.X., and Pei, Z.J., 2010, "Ultrasonic vibration assisted pelleting of wheat straw: effects of particle size," Proceedings of the 20th International Conference on Flexible Automation and Intelligent Manufacturing (FAIM 2010), California State University, CA, July 12-14.

[38] Nottingham, D., Pei, Z.J., Deines, T.W., and Zhang, M., 2010, “The effects of pelleting time and ultrasonic power during ultrasonic vibration-assisted pelleting of switchgrass," Proceedings of the IIE Annual Conference and Expo 2010, Cancun, Mexico, June 5-9. 
Table 1.Experimental conditions.

\begin{tabular}{ccccc}
\hline $\begin{array}{c}\text { Pelleting duration } \\
(\mathrm{s})\end{array}$ & $\begin{array}{c}\text { Ultrasonic } \\
\text { power }(\%)\end{array}$ & $\begin{array}{c}\text { Pelleting } \\
\text { pressure }(\mathrm{psi})\end{array}$ & $\begin{array}{c}\text { Pellet weight } \\
(\mathrm{g})\end{array}$ & $\begin{array}{c}\text { Moisture content } \\
(\%)\end{array}$ \\
\hline $30,60,90,120,150$ & 50 & 40 & 2.0 & 10 \\
120 & $40,50,60,70$ & 40 & 2.0 & 10 \\
120 & 50 & $20,30,40,50$ & 2.0 & 10 \\
120 & 50 & 40 & $1.5,2.0,2.5,3.0$ & 10 \\
120 & 50 & 40 & 2.0 & $5,10,15,20$ \\
\hline
\end{tabular}




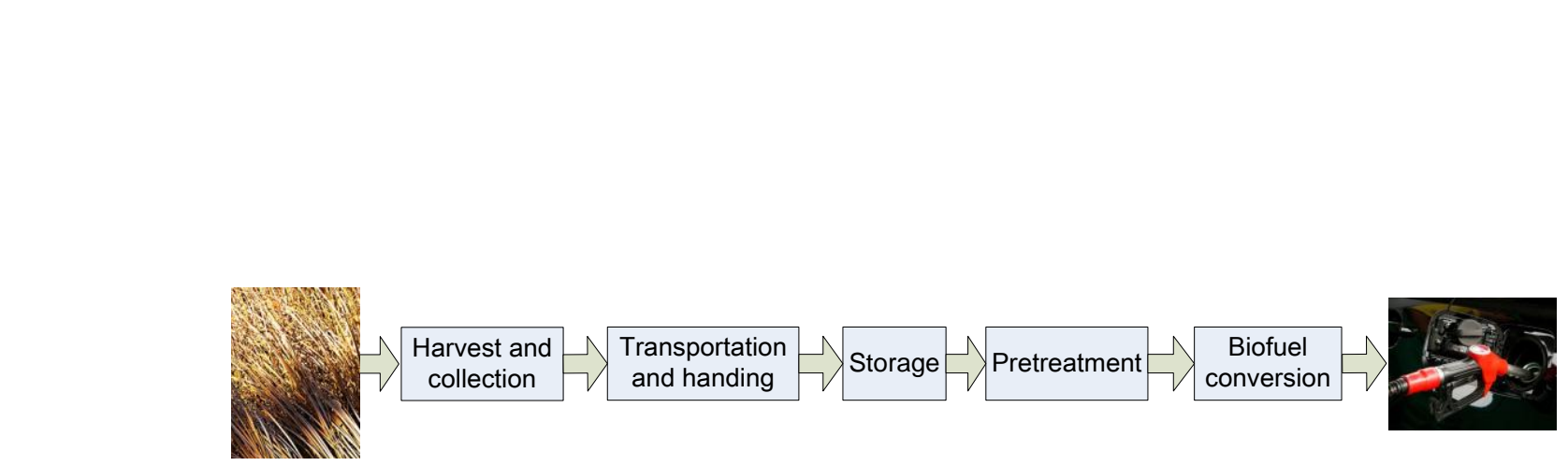

Figure

\section{Figure}

\begin{tabular}{|c|c|c|c|c|}
\hline $\begin{array}{c}\text { Harvest and } \\
\text { collection }\end{array}$ & $\begin{array}{l}\text { Transportation } \\
\text { and handing }\end{array}$ & Storage & Pretreatmen & $\begin{array}{c}\text { Biofuel } \\
\text { conversion }\end{array}$ \\
\hline
\end{tabular}

.

\section{Figure 1. Major steps for manufacturing of cellulosic biofuels (after [8, 9]).}



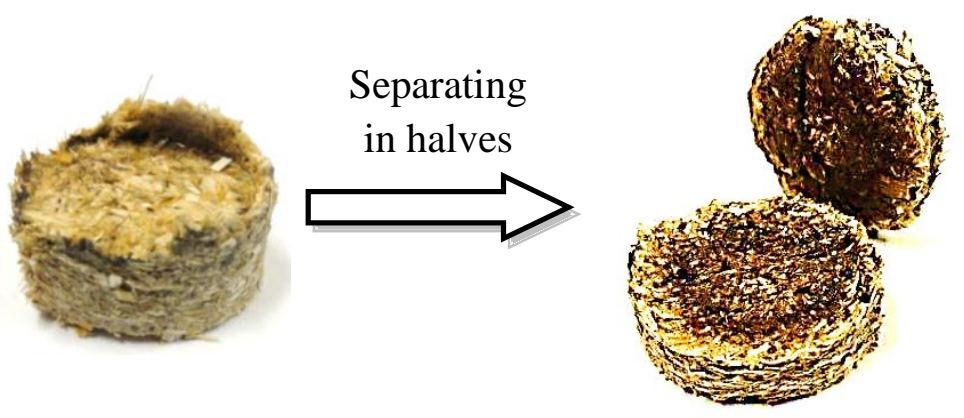

Figure 2. Charring occurred inside pellets in UV-A pelleting. 


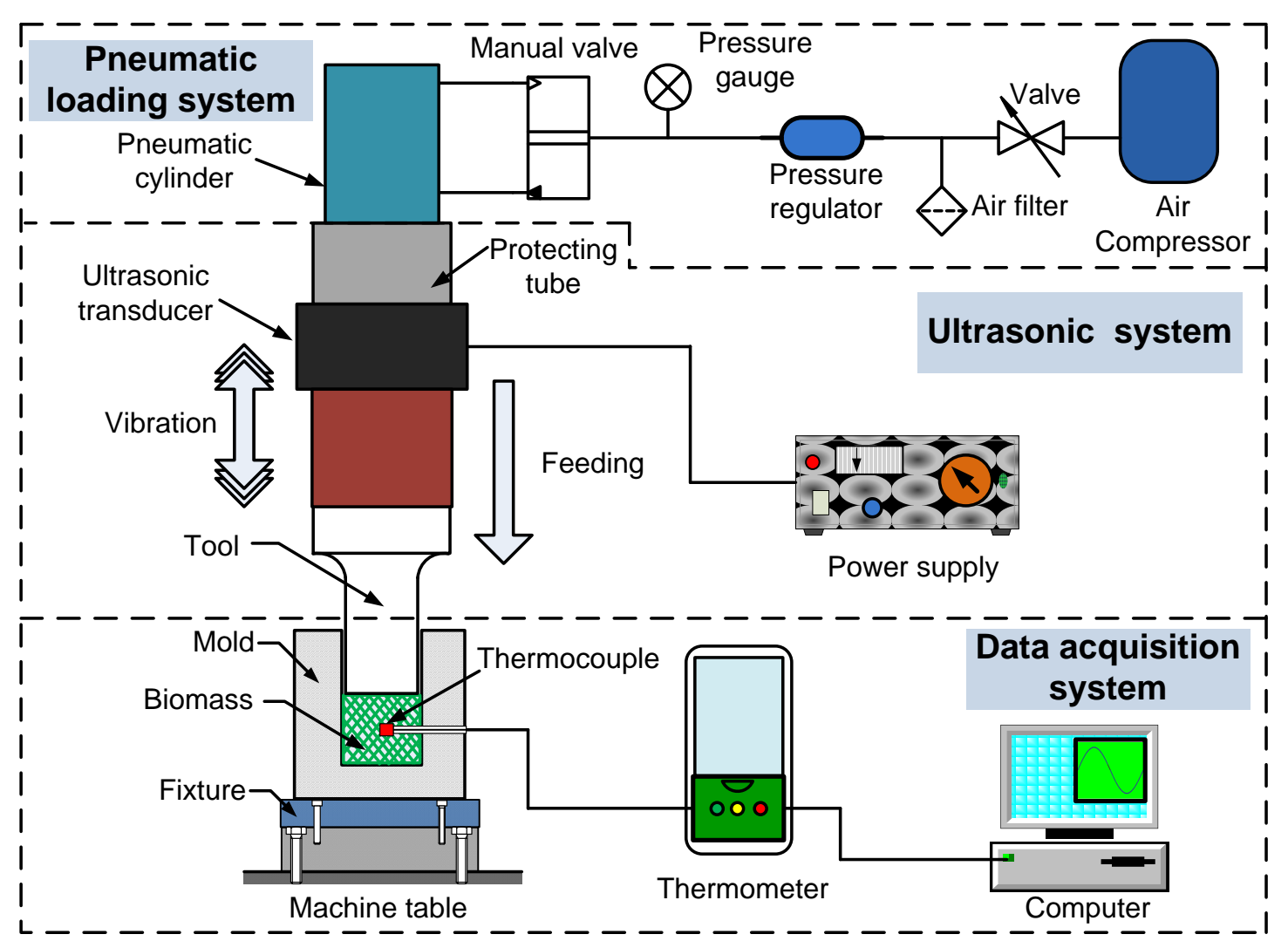

Figure 3. Experimental setup of UV-A pelleting. 


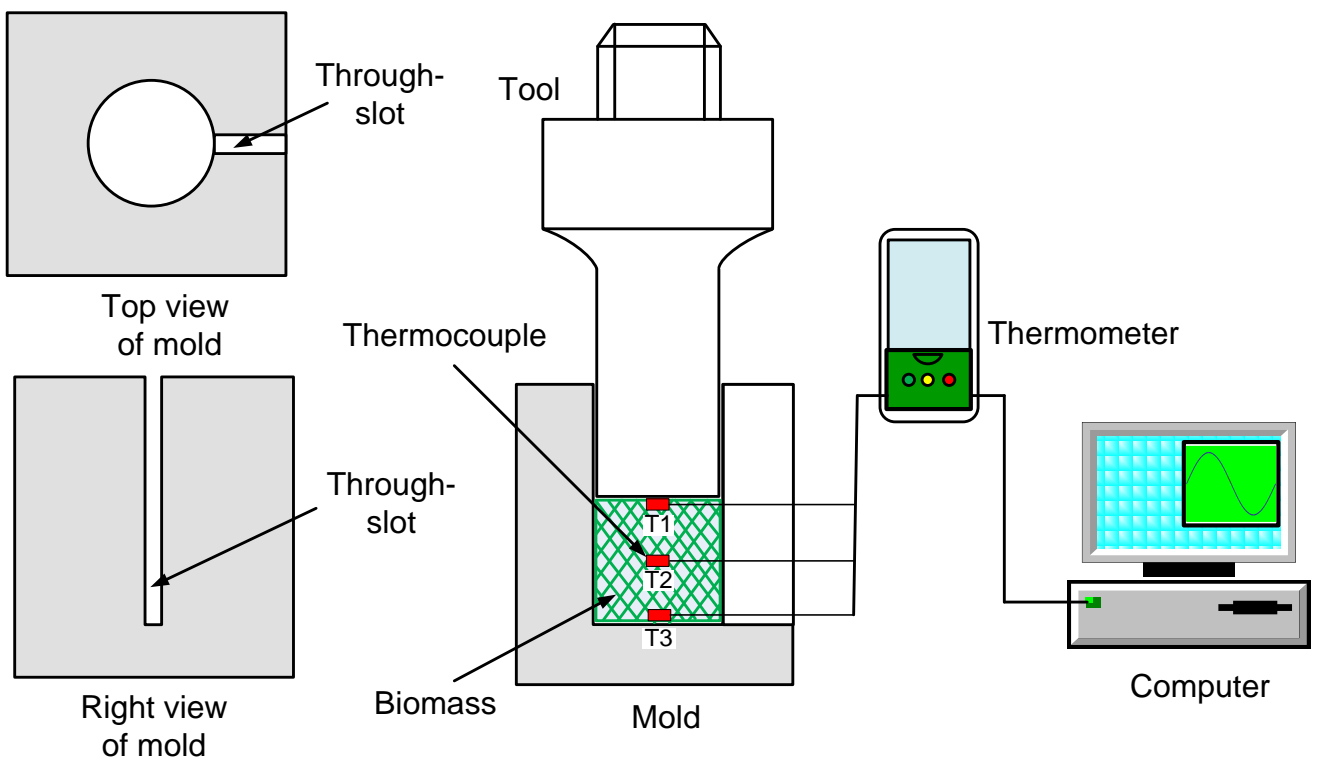

Figure 4. Illustration of temperature measurement in UV-A pelleting. 


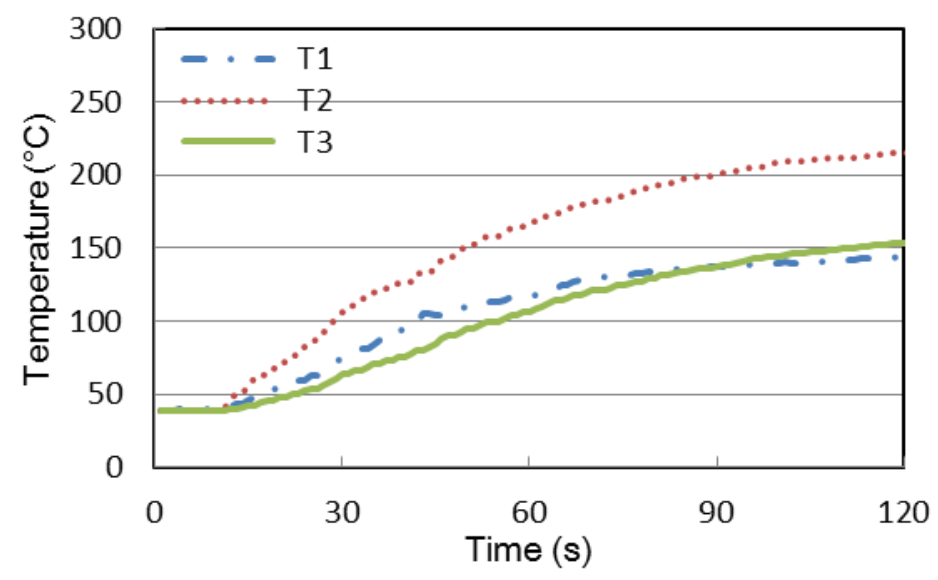

Figure 5. Temperature versus time curves with $40 \%$ ultrasonic power.

(Pelleting duration $=120 \mathrm{~s}$, Pelleting pressure $=40 \mathrm{psi}$, Pellet weight $=2.0 \mathrm{~g}$, and Moisture content $=10 \%$.)

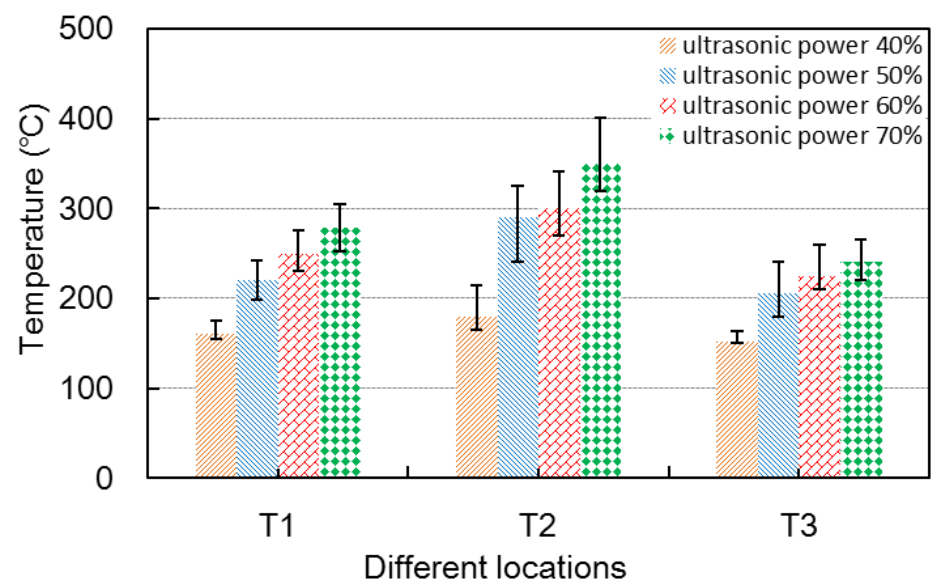

Figure 6. Effect of ultrasonic powers on pelleting temperatures at different locations.

(Pelleting duration $=120 \mathrm{~s}$, Pelleting pressure $=40 \mathrm{psi}$,

Pellet weight $=2.0 \mathrm{~g}$, and Moisture content $=10 \%$.) 


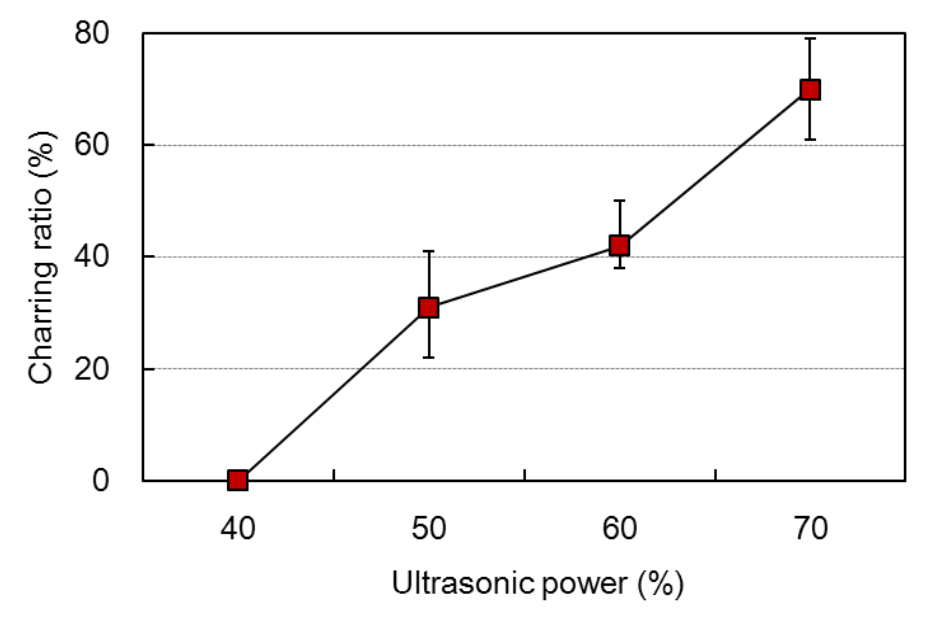

a. Effect on charring ratio.

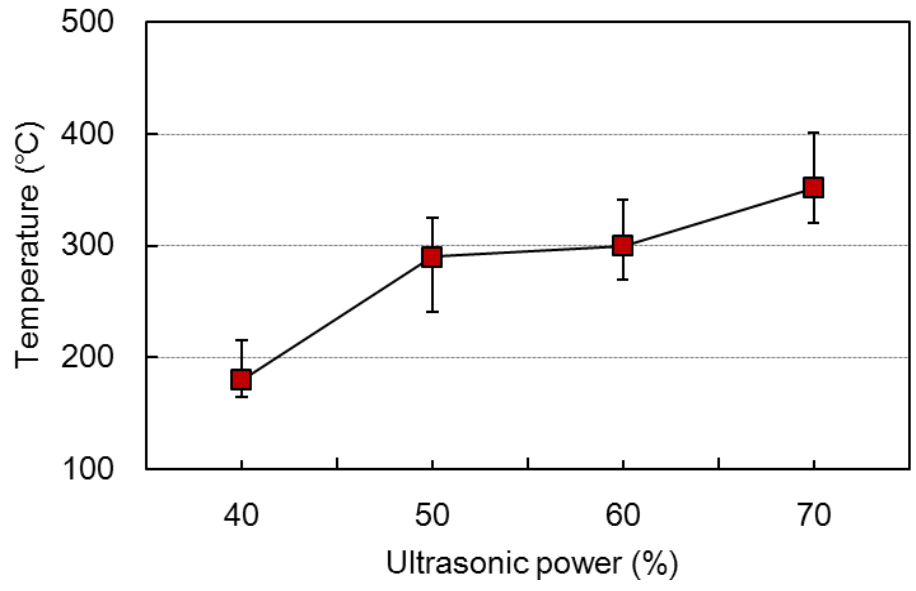

b. Effect on pelleting temperature.

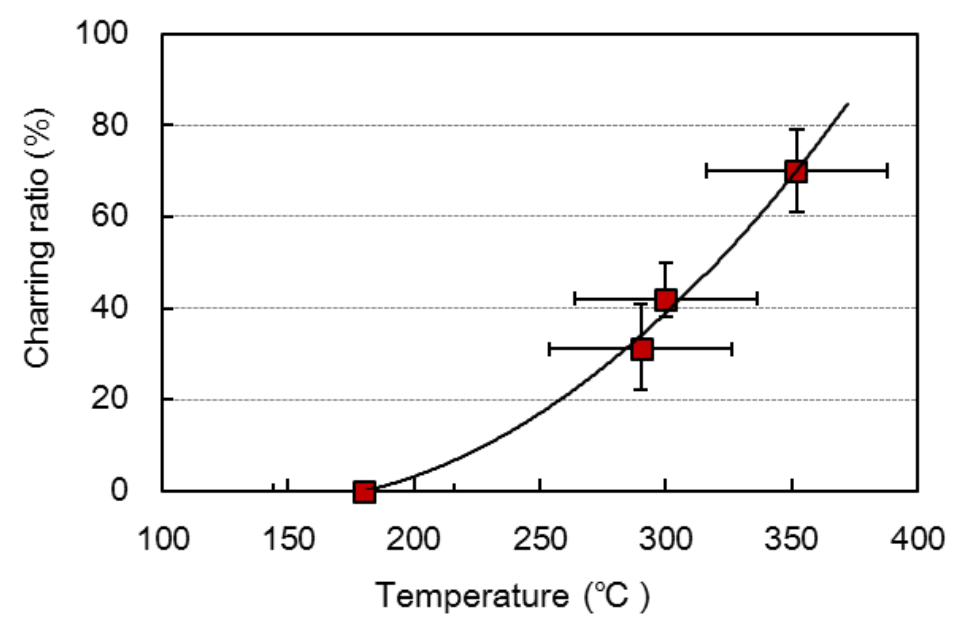

c. Relationship between charring ratio and temperature.

Figure 7. Effects of ultrasonic power.

(Pelleting duration $=120 \mathrm{~s}$, Pelleting pressure $=40 \mathrm{psi}$, Pellet weight $=2.0 \mathrm{~g}$, and Moisture content $=10 \%$.) 


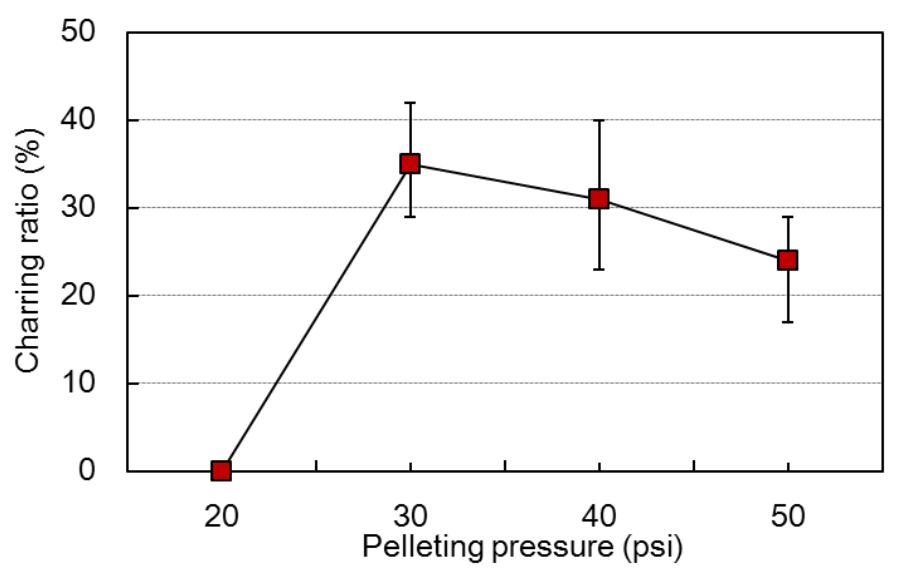

a. Effect on charring ratio.

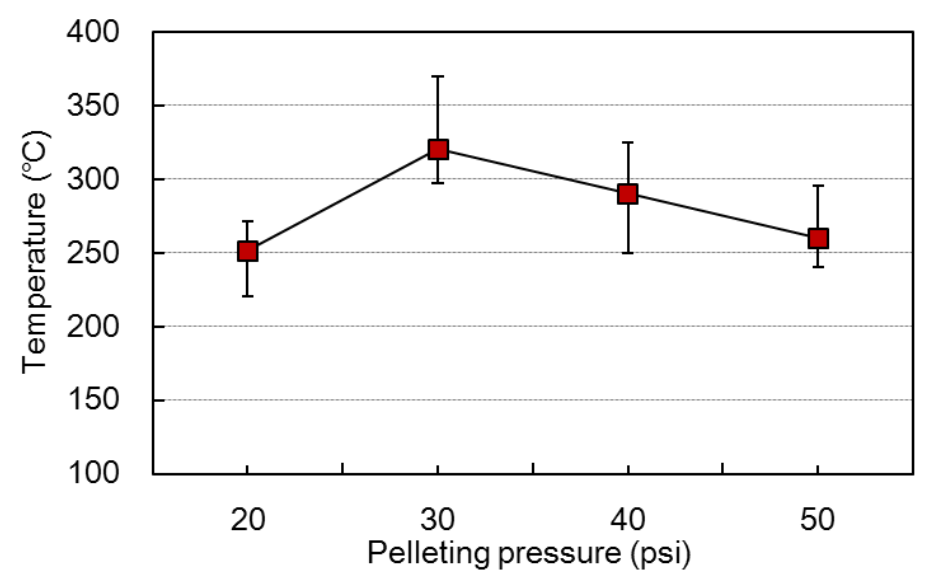

b. Effect on pelleting temperature.

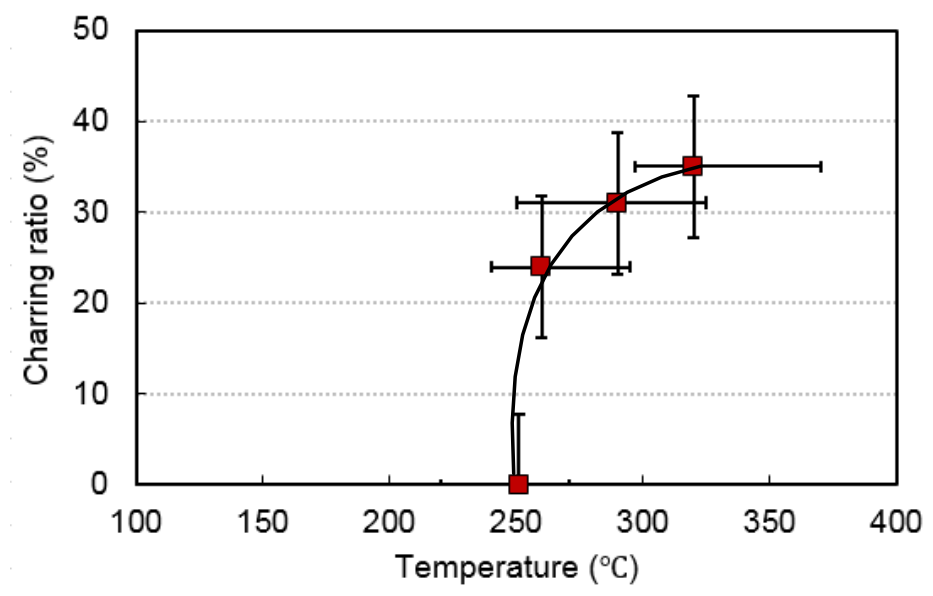

c. Relationship between charring ratio and temperature.

Figure 8. Effects of pelleting pressures.

(Pelleting duration $=120 \mathrm{~s}$, Ultrasonic power $=50 \%$,

Pellet weight $=2.0 \mathrm{~g}$, and moisture content $=10 \%$.) 


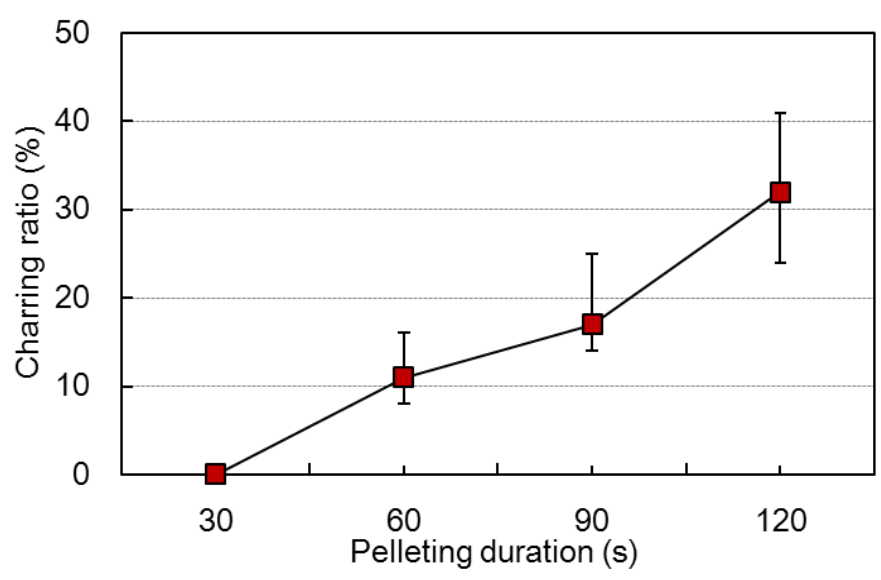

a. Effect on charring ratio.

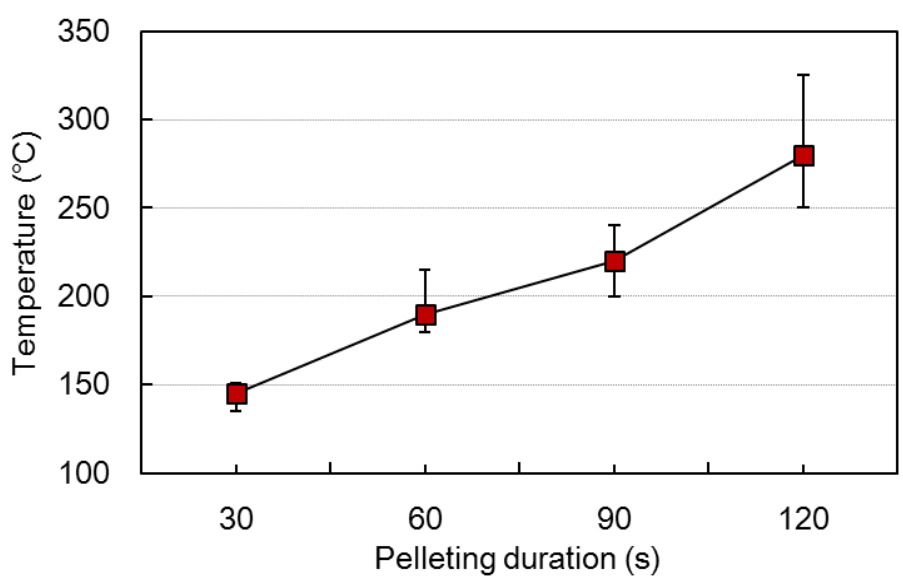

b. Effect on pelleting temperature.

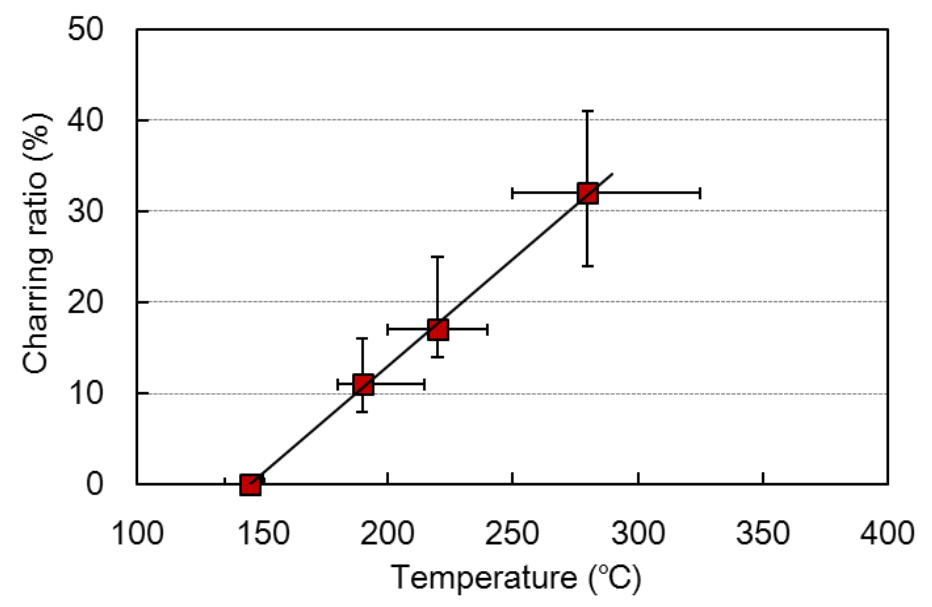

c. Relationship between charring ratio and temperature.

Figure 9. Effects of pelleting duration.

(Ultrasonic power $=50 \%$, Pelleting pressure $=40 \mathrm{psi}$,

Pellet weight $=2.0 \mathrm{~g}$, and Moisture content $=10 \%$.) 


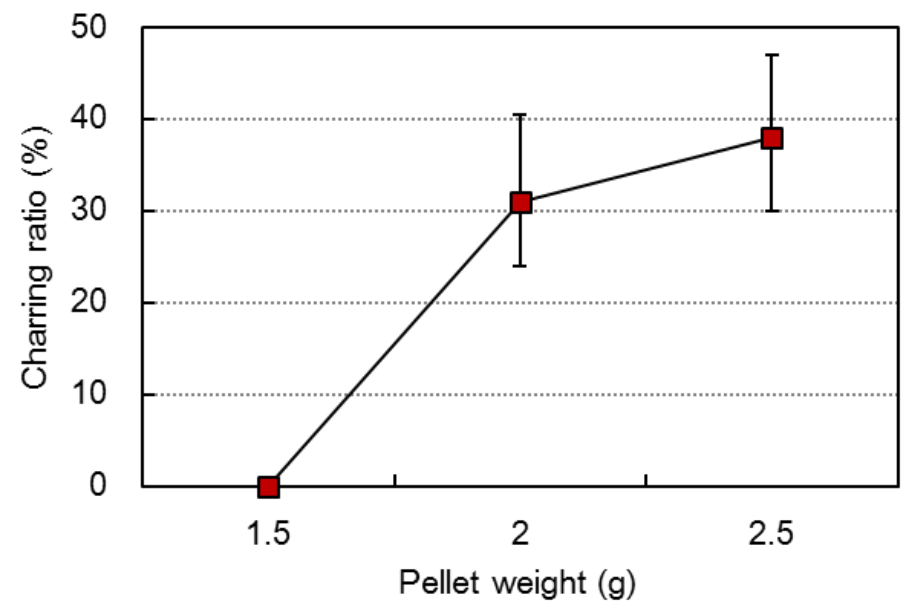

a. Effect on charring ratio.

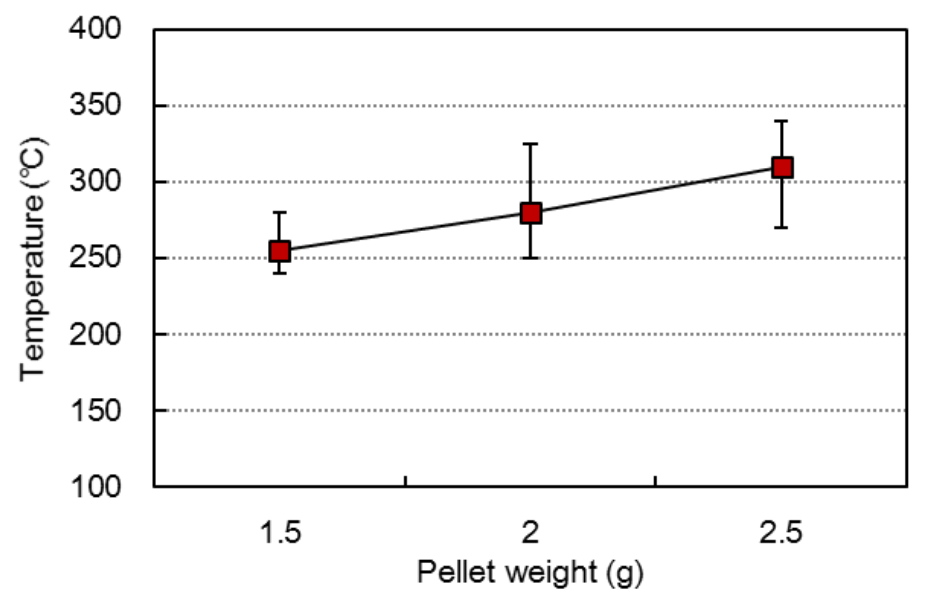

b. Effect on pelleting temperature.

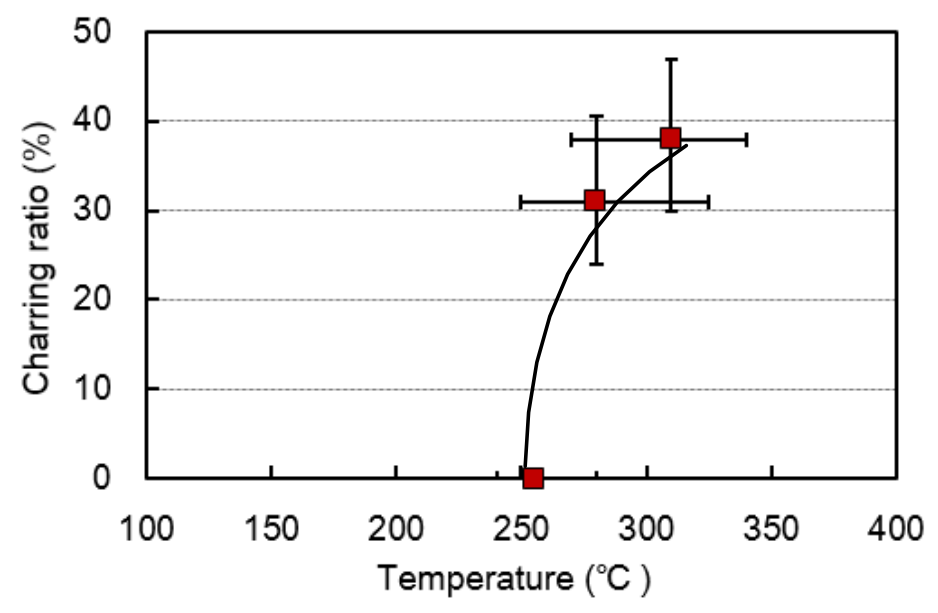

c. Relationship between charring ratio and temperature.

Figure 10. Effects of pellet weight.

(Pelleting duration $=120 \mathrm{~s}$, Ultrasonic power $=50 \%$, Pelleting pressure $=40 \mathrm{psi}$, and Moisture content $=10 \%$.) 


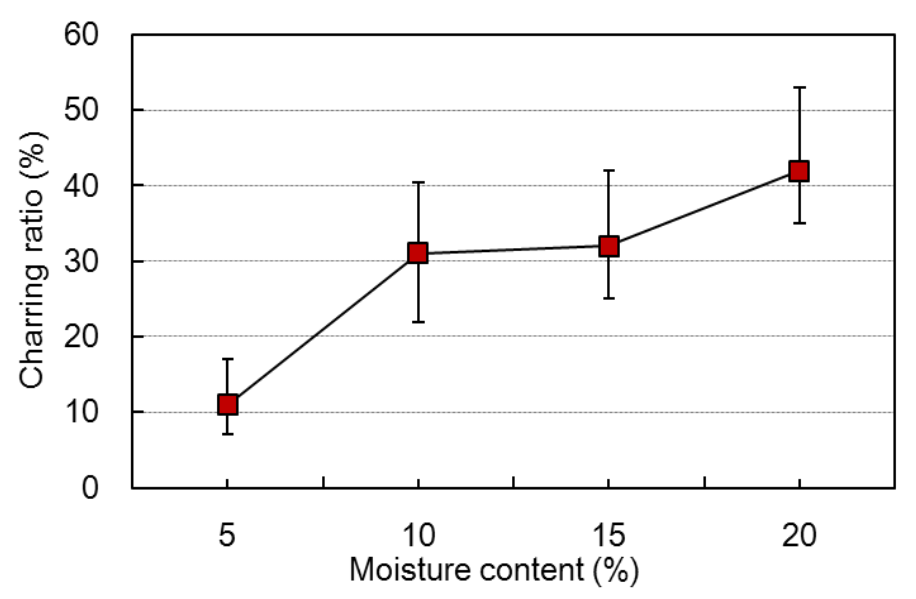

a. Effect on charring ratio.

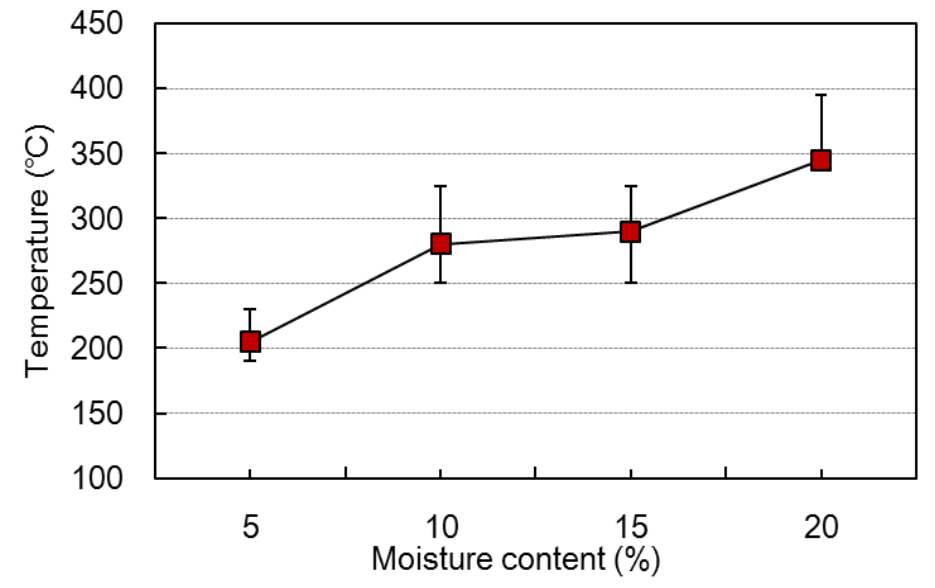

b. Effect on pelleting temperature.

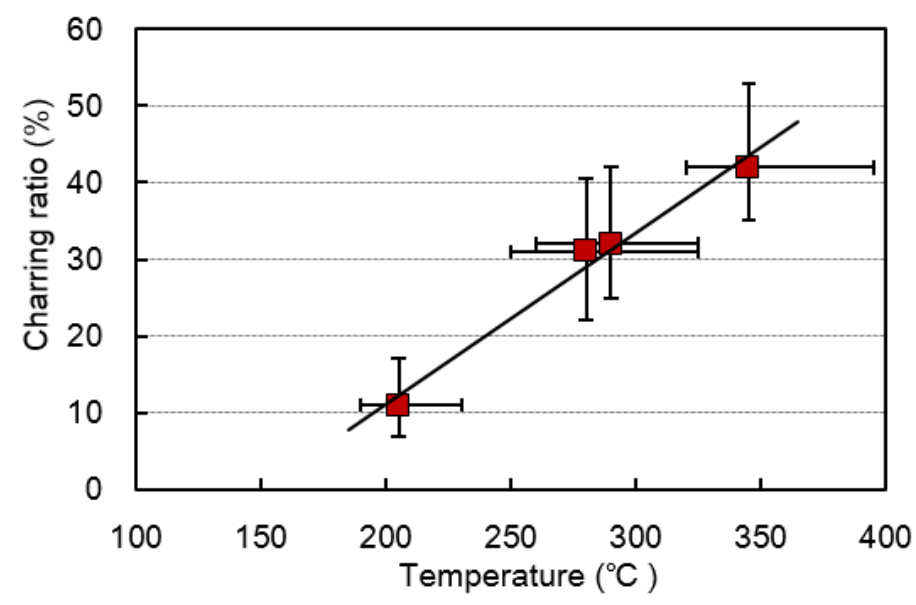

c. Relationship between charring ratio and temperature

Figure 11. Effects of moisture content. 


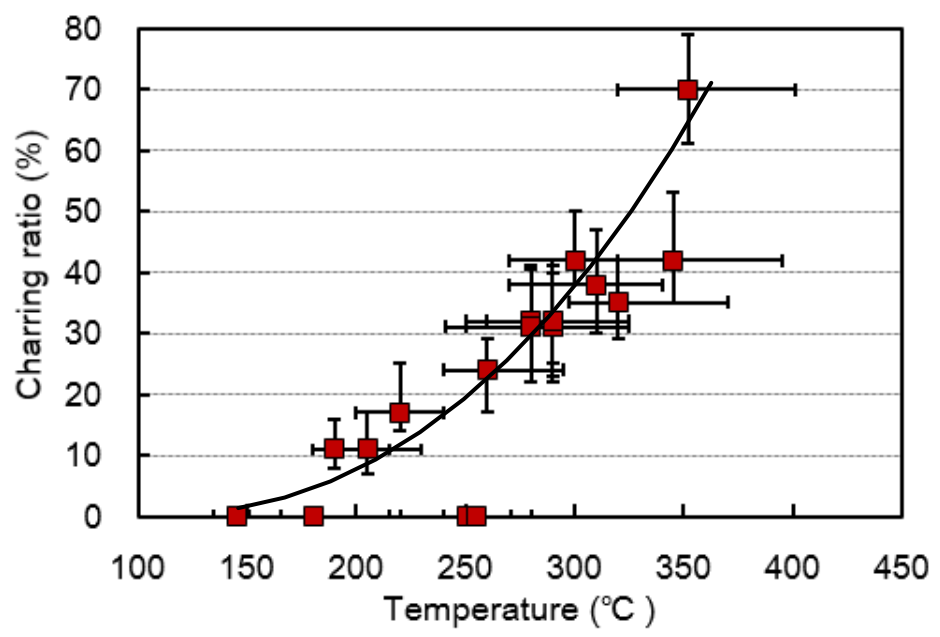

Figure 12. Global overviews on relationship between charring ratio and pelleting temperature. 